\title{
Things New Graduate Nurses Should Remember from Fundamentals
}

\author{
Eliadi Carol* \\ Dean of Nursing Worcester, Professor of Nursing, MCPHS University, USA
}

Received: 㘹August 01, 2018; Published: 盋 August 06, 2018

*Corresponding author: Eliadi Carol, Dean of Nursing Worcester, Professor of Nursing, MCPHS University, USA

\begin{abstract}
Moving from the protective walls of a nursing program to independent nursing practice can be a sobering transition for many new graduates. Many new nurses may feel overwhelmed and insecure as they embark on the work world and the responsibility of becoming a licensed nurse. The growth of knowledge and the complexity of the nursing profession makes it impossible for a new nurse to graduate from school with all the skills and abilities necessary to function independently in the complex world of patient care. Developing clinical competency and a comfort level with your nursing practice skills represent a major challenge for entry level nurses. This core knowledge is essential in order for you to provide timely, sensitive, safe, and quality care to the patients with whom you work. As you prepare to enter the health care arena and accept responsibility and accountability for patient care, please remember these important concepts from your fundamental nursing courses that can help you in developing a strong foundation for safe professional nursing practice
\end{abstract}

\section{Vital Signs}

\section{Factors Affecting Pulse}

a) Age: As age increases, pulse decreases

b) Gender: After puberty, average male's pulse rate is slightly lower than the female's

c) Exercise: Pulse rate increases with activity and decreases in athletes

d) Fever: Pulse increases with increased metabolic rate

e) Medications: Cardiotonics [digitalis preparations] will decrease the heart rate, epinephrine will increase the heart rate

f) Hypovolemia: loss from vascular system normally increases pulse rate

g) Stress: sympathetic nervous system stimulation increases heart rate

h) Position Changes: blood pools in dependent vessels of the venous system, when patient sits/stands blood pressure will decrease, and heart rate will increase- Orthostatic Hypotension

i) Pathology: certain diseases such as some heart conditions or those that impair oxygenation can alter the resting pulse rate [1].

\section{Factors Affecting Blood Pressure}

a) Age: Newborns have a mean systolic BP of $75 \mathrm{~mm}$ hg. Pressure rises with age and then tends to decline after puberty. Elders have elevated systolic BP due to decreased elasticity of the arteries

b) Exercise: Physical activity increases cardiac output thus; 2030 minutes of rest following exercise is indicated before assessing resting blood pressure

c) Stress: Stimulation of sympathetic nervous system increased cardiac output and vasoconstriction of the arterioles, thus increasing BP, severe pain can decrease BP by inhibiting the vasomotor center and producing vasodilatation

d) Race: African American males $>35$ have higher BP than European males of the same age

e) Gender: After puberty, females usually have a lower BP than males. After menopause women generally have higher BP than before

f) Medications: Many medications, including caffeine, may increase or decrease the BP 
g) Obesity: Both childhood and adult obesity predisposes one to hypertension

h) Diurnal variations: BP usually lowest in the early morning when metabolic rate is low and rises and peaks in late afternoon

i) Disease processes: Any condition affecting the cardiac output, bold volume, blood viscosity, and/or compliance of the arteries has a direct effect on the BP [2].

\section{Factors Affecting Oxygen Saturation}

a) Hemoglobin: If the hemoglobin is fully saturated with oxygen, the Sao2 will appear normal even if the total hemoglobin is low such as in the case of severely anemic patients

b) Circulation: The oximeter will not return an adequate reading if the area under the sensor has impaired circulation

c) Activity: Shivering or excessive movement of the sensor can interfere with an accurate reading

d) Carbon monoxide poisoning: Pulse oximeters cannot discriminate between hemoglobin saturated with carbon monoxide versus oxygen thus requiring other measurements of oxygenation [3].

f) Environment: Extremes in environment can affect a person's temperature regulatory systems [2] (Table 1).

Table 1: Selected Sources of Errors in BP Assessment.

\begin{tabular}{|c|c|}
\hline Error & Effect \\
\hline Bladder cuff too narrow & Erroneously high \\
\hline Bladder cuff too wide & Erroneously too low \\
\hline Arm unsupported & Erroneously high \\
\hline Insufficient rest before $\mathrm{BP}$ & Erroneously high \\
\hline Repeating BP too quickly & Erroneously high systolic or low diastolic \\
\hline Cuff too lose & Erroneously high \\
\hline Deflating cuff too quickly & Erroneously high diastolic \\
\hline Deflating cuff too slowly & Erroneously high diastolic \\
\hline Failure to use same arm consistently & Inconsistent measurements \\
\hline Arm above heart level & Erroneously low \\
\hline Assessing after meal, smoking or while in pain & Erroneously high \\
\hline Failure to identify ausculatory gap & Erroneously low systolic and erroneously Low diastolic \\
\hline
\end{tabular}

\section{Intravenous Site Management}

a) Fluid Infiltration: localized swelling, coolness, pallor and discomfort at the IV site. Remove IV catheter and restart at another site. Apply warm compress

b) Phlebitis: redness, warmth and swelling at the IV site and burning pain along the course of the vein. Discontinue the infusion and apply warm compresses. Do not use this injured vein for further infusions.

\section{Factors Affecting Body Temperature}

a) Age: Infant temperature is affected by the environment and are more variable than adults up until puberty; older people are at risk for hypothermia and are particularly sensitive to extremes in the environmental temperature due to decreased thermoregulatory controls

b) Diurnal rhythms: Body temperature can change throughout the day be as much as 1.0-degree $\mathrm{C}$ and 1.8-degree $\mathrm{F}$. Highest temperature is between 1400-1600 hours and the lowest temperature is between 0400-0600

c) Exercise: Hard work or strenuous exercise can increase the temperature to 38.3 t0 40 degrees C or 101 to 104 degrees F

d) Hormones: women experience more hormone fluctuation than men and body temperature can rise by about 0.3 to 0.6 degrees C $(0.5$ to 1.0 degrees $\mathrm{F}$

e) Stress: Stimulation of the sympathetic nervous system can increase the production of epinephrine and norepinephrine thus increasing metabolic activity, heat production and body temperature

\section{Indwelling Catheters}

\section{Preventing Catheter Associated Infections}

catheterize patients only when necessary by using aseptic technique; maintain a closed system; do not disconnect the drainage tubing from the catheter to obtain specimens; remove the catheter as soon as possible, follow and reinforce hand hygiene, provide routine perineal care, prevent contamination of the catheter with feces and DO NOT place the collection bag on the bed or stretcher 
or lap of the patient during transport! The collection bag should always be kept below waist level.

\section{Safety}

\section{Preventing Puncture Injuries}

Use appropriate puncture proof disposal containers to dispose of uncapped needles and sharps; never throw sharps in the waste basket; utilize safety syringes [passive or active] whenever possible; never bend or break needles before disposal; never recap used needles; when necessary to recap a needle, use the one handed "scoop method."

\section{Preventing Back Injuries}

Avoid lifting anything more than 51 pounds, use assistive devices, and get help from co-workers. Become consciously aware of your posture and body mechanics. When standing for a long period of time, periodically move legs and hips. Rest your foot on an object if possible. When sitting, keep you knees slightly higher than your hips. Exercise regularly to maintain overall physical condition. Avoid movements that cause or require spinal flexion with straight legs (toe touching or sit ups) or spinal rotation (twisting). When moving an object, distribute the weight between large muscles of the arms and legs, limiting the load to 15-25 pounds held at elbow height. Wear comfortable low-heeled shoes that provide good foot support and reduce the risk of slipping, stumbling or turning your ankle [2].

Postscript: Take a deep breath and let go of unrealistic expectations and recognize that perfection is impossible. Replace self-doubting feelings with the notion that it is normal to feel nervous and reflect on past experiences in class, lab and clinical that prove you can complete the task at hand. Keep track of your accomplishments and embrace your success. You have earned the right to be here through your abilities and hard work. Remember to ask for help. Being able to ask for help is a valuable attribute and does not diminish your accomplishments. Finally, do not dwell on failure or criticism. Learn from the experiences and move on.

\section{References}

1. Jarvis Carolyn (2016) Physical examination and health assessment. Saunders/Elsevier. St. Louis, Missouri.

2. Kozier B (2017) Fundamentals of nursing $8^{\text {th }}$ edition. Pearson Prentice Hall. Upper Saddle River, New Jersey.

3. Potter, Patricia, Perry Anne (2014) Fundamentals of nursing. Elsevier/ Mosby. St. Louis, Missouri.

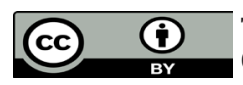

This work is licensed under Creative Commons Attribution 4.0 License

To Submit Your Article Click Here: Submit Article

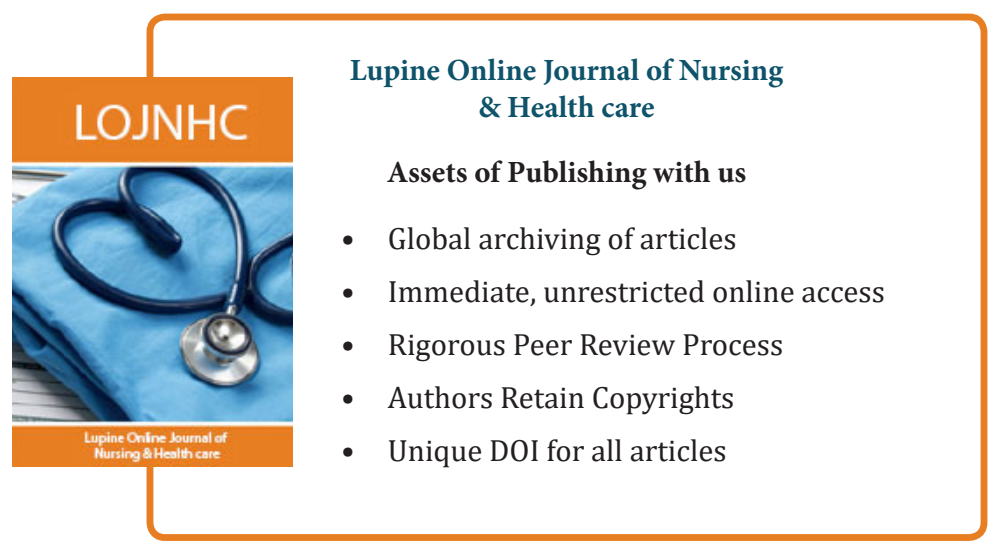

